Theories \& Applications, the International Edition

Printed Version : (ISSN 2090-5262)

Online Version : (ISSN 2090-5270)

July 2014, Volume 4, No. 2 Pages (51 - 66)

\title{
Developing Specific Exercises through Studying Electrical Activity of some Muscles Working on the Lower Limb during Triple Jump Competition.
}

\section{Dr. Magda Nagy Nasr}

Assistant professor, Department of Sports Training and Movement Sciences, Faculty of Physical Education for Girls, Alexandria University, Egypt.

\begin{abstract}
Technological development have a big share in kinematic analysis, as in measuring muscle electrical activity, in detection of inter-relationships between body parts of the body while performing those skills. This could not be obtained without followup and analyze player movements during skills' performance phases .

Exercises which are similar to skills performance nature should be similar in motor composition with movements performed by player within sports competition in terms of force, speed, force time path, muscular work direction and with movements performed, i.e. characterized with existence of dynamic match between its the path and motor technique path using the same working muscle groups in the same skill .

Exercise which is characterized by privacy in the development of physical and motor abilities, in certain muscles in the body, where it works on the immediate focus on working muscles and improve muscle tone and timing of contraction and extraversion necessary for sound performance; that indicate using specific exercises importance to upgrade skills performance level in various sports activities, these exercises serve skills performance and improve neuromuscular path of its performance.

Researcher in the opinion that determine specific exercise through analysis using (EMG) and mechanical analysis work to give coaches the opportunity to choose - on scientific grounds - specific exercises associated with activity practiced, where it is difficult to make the equipment available for coaches, so the researcher analyzed the competition for Egypt champion under 18 years in triple jump, as well as propose a set of exercises that are similar to performance, analyze and compare the performance of triple jump to determine the most important specific exercises related to performance. Determining working muscle in practiced activity helps coaches too much on developing sound training programs, which aimed to develop functional status of these muscle specifically.

The most important results include that the most important muscle are Quadriceps femoris muscle - vastus lateralis, Quadriceps femoris muscle - vastus medialis, Gastrocnemius muscle - lateral part, and Tibialis anterior muscle and that That most important muscles working in (1st and 2nd) exercises vastus are Quadriceps femoris muscle - vastus lateralis, Quadriceps femoris muscle - vastus medialis, Gastrocnemius muscle - lateral part, Tibialis anterior muscle and Quadriceps femoris muscle - rectus femoris which are the same working muscles in triple jump and almost with the same of maximum contraction values. Working muscles (3rd, 4th and 5th) were Quadriceps femoris muscle - vastus lateralis, Quadriceps femoris muscle - vastus medialis, Gastrocnemius muscle - lateral part, and Tibialis anterior muscle
\end{abstract}

\section{Introduction:}

$\mathrm{D}$ eveloped countries were able to reach the optimal use of players' abilities within each phase of skill technical performance phases through specific exercises which are similar of movements in its composition, requirements, work direction, muscles contractions prevailing in working muscle groups in it with those movements that done through performance, which leads to economy in the time and effort until reaching mastery of motor skills in activity type. (Khairia ELsokry, Mohammed Briqa, 2010: p79)

Abul Ela Abdel Fattah, Mohamed Sobhy Hassanein (1997, P35) noted that technological development have big shares in kinematic analysis, in measuring muscle electrical activity, in detection of the inter-relationships between parts of the body while performing those skills. This could not be obtained without follow-up and analyze of player movements during skills' performance phases.

Talha Hussein, Mohammed Abdel-Rahman (1989, p36-37) argue that using anatomical analysis for muscular system is one of the scientific methods to study muscles contact locations and their relationship with joints; also it helps coach to identify the most important muscles that work positively to perform a movement; so the coach can through this knowledge - develop muscles function in an appropriate manner; which in turn makes player able to perform and progress to optimal level

Electromyography (EMG) is working to find out contribution extent of each working muscle's in the movement, as well as the changes occur in muscles during acquiring motor skills . 
Talha Hossam El Din (1994, p17-18) confirm the importance of specific exercises, which means that kind of exercise, which is characterized by privacy in the development of physical and motor abilities, in certain muscles, where it works on the immediate focus on working muscles and improve muscle tone and contraction timing and extraversion necessary for sound performance; that indicate using specific exercises is important to upgrade skills performance level in various sports activities, these exercises serve skills performance and improve its performance neuromuscular path.

Mohamed Hassan Allawi (1990, p294) and Essam AbdelKhalek $(1994$, p18) in the opinion that exercises which are similar to skills performance nature are similar in motor composition with movements performed by player within a sports competition in terms of force, speed, force time path, muscular work direction and with movements performed, i.e. characterized with existence of dynamic match between its the path and motor technique path using the same working muscle groups in the same skill.

Triple jump consists of the following stages: approach, hop, step and jump. Each of hop, step, and jump consists of takeoff, flight and landing. (4: 88). Qassim Hassan (1999, p335) indicates that triple jump is made from approaching and three interconnected jumps where takeoff force plays major role in the jump. Bastawisy Ahmad (1997, p318-319) also confirms that force and speed elements represent a positive and important role in triple jump for three jumps in a row with different rhythms, this means a difference in mechanical foundations application which affect achievement level of the three jumps. Therefore it should be taken into account to get the proper angle whether at setting foot, or while impulse at take-off stage, to get center of gravity at the highest speed ratio, coupled with the most appropriate angle of flight, center of gravity should arrive to appropriate flight height to achieve the greatest possible distance.

After examining scientific literature, previous studies and what has been obtained from the internet; the information associated with research matter indicate that there are many studies used plyometric exercises training programs to develop muscle force as studies of Samir Abbas, Omar Abdel Moneim, Ibrahim Hareedy (1987), which studied the effect of two methods of plyometric exercises on the relative force for lower limp and six hops distance and time, Osama Mohammed Abu Tabl (1999), which studied the effect of plyometric exercises standardization using ability analysis on some dynamic performance variables in triple jump competition, Ahmed Saad, Osama Abu Tabl (2008), which focused on combining plyometric training with electrophoresis on some muscle strength characteristics and record level at triple jump races (3). Some studies used training programs to develop muscle strength in horizontal and vertical direction as studies of: Mohamed Shawky Sibai, Amr Allah Bisatti (2002), Mohamed Mohamed Abdel Aal, Abdel Moneim Ibrahim Hareedy, ElSayed Shehata Ahmed (2001), Yu Ping (1999), Abdel Moneim Ibrahim Hareedy,
Ahmed Saad Eddin Mahmoud (1999), which examined development of muscle strength in several knee joint angles and its impact on achievement of the triple jump competition ".

JARMO eta al (2000) study was designed to assess neuromuscular work through muscles electrical activity in the triple jump competition using (EMG), W. Kakihana Suzuki \& S. Suzuki (2001) study aimed to describe land reaction through (EMG) and kinematic variables during takeoff in different angles in triple jump, Walker. S, et al (2011) study aimed to compare fixed and variable resistors repetition using group loads, speeds and contractions, Cassie.W, et al (2009) studied kinetic models for triple jump exercises and aimed to determine the effectiveness of training on lower limb exercises models used for triple jump .

In light of what mentioned above, the researcher in the opinion that determine specific exercise through analysis using (EMG) and mechanical analysis work to give coaches the opportunity to choose - on scientific grounds - specific exercises associated with sport activity practiced, where it is difficult to make the equipment available for coaches, so the researcher analyzed the competition for Egypt champion under 18 years in triple jump, as well as propose a set of exercises which are similar to performance, analyze and compare the performance of triple jump to determine the most important specific exercises related to performance, as determining working muscle in practiced activity type helps coaches too much on developing sound training programs, which aimed to develop functional status of these muscle specifically.

\section{Research objectives :}

1- Identify the electrical activity of some lower limb muscles to improve take off phase (hop - step jump) in the triple jump competition .

2- Suggestion quality exercises to improve takeoff phase (hop - step - jump) in the triple jump competition .

3- Identify the electrical activity of some lower limb muscles in takeoff phase (hop - step - jump) in the proposed exercises .

4- Identify the most important specific exercises involving muscles that work in takeoff phase (hop step - jump) for the triple jump competition .

5- Identify some biomechanics variables for Egypt champion under 18 years in takeoff phase (hop- step - jump) and their relationship to electrical activity of some lower limp muscles of triple jump competition.

\section{Research queries :}

1- What is the relative importance of some lower limb muscles to improve take off phase (hop - step jump) in the triple jump competition? 
2- What is the relative importance of some lower limb muscles in takeoff phase (hop - step - jump) in the proposed exercises?

3- What are the working muscles in takeoff phase (hop - step - jump) for the triple jump competition?

4- What are the biomechanics variables for Egypt champion under 18 years in takeoff phase (hop- step - jump) and their relationship to electrical activity of some lower limp muscles of triple jump competition.

\section{Research procedures :}

\section{I- Research Methodology :}

The researcher used descriptive approach with muscle activity analysis and mechanical analysis due to its relevance to the nature of this search .

\section{II- Research Sample}

Selected intentionally Egypt champion (female) under 18 years in the triple jump and the player at Alexandria military establishment Club for year 2012 .

Table (1)

player's Data

\begin{tabular}{|c|c|}
\hline Name & Reham Hamdy \\
\hline Hight & $171 \mathrm{~cm}$ \\
\hline Weight & 59 kg \\
\hline Date of birth & Sept $18^{\text {th }}, 1997$ \\
\hline Years of training & 5 years \\
\hline Record & $11.81 \mathrm{~m}$ \\
\hline
\end{tabular}

\section{III- Research Tools :}

- Muscle electrical drawing device (EMG) Wireless with 16-channel .

- 2 video camera (one for analysis of muscles' electrical activity and the other for kinematic analysis) with frequency of 25 cadre / sec .

Analysis instruments and devices represented in

1- Siemens computer device contains :

- Kinetic Analysis Software and includes three main programs :
A- Streampix recording software
B- AVI Editing program
C- Win analyze 2 dimension 2D

\section{2- Computer.}

3 - Laser printer .

- Restameter for height measurement to nearest 0.5 $\mathrm{cm}$.

- Different height barriers $30 \mathrm{~cm}, 40 \mathrm{~cm}$, jump box, Medical balls Weight $2 \mathrm{~kg}$, boxes with height of 17 $\mathrm{cm}$.
- Medical scale to measure weight to the nearest 0.5 $\mathrm{kg}$.

\section{III- Pilot study :}

Pilot study conducted for vediograph competition and proposed exercises under discussion :

Pilot study had been applied on $4^{\text {th }}$ grade student, Department of track and Field, Faculty of Physical Education for Girls, Alexandria University, who are not in main study sample, this study was conducted on Saturday May $26^{\text {th }}, 2012$ at 11 am in track and field land in faculty Physical of Physical Education for Girls, Alexandria University, in order to :

- Ensure the validity of land area that will be used .

- Determine cameras location, speed and height positions .

- Make sure that the cameras are perpendicular to motion field and include overall movement area

- Identify drawing scale .

- Detection of problems that may appear during videography to avoid any error .

- Make sure that assistants know how to use measuring instruments .

The results revealed:

- Ensuring safety and efficiency measurement tools.

- Muscle Electric Analysis camera (1) and its videography area of takeoff, flight and landing phases $(16.85 \mathrm{~m})$ and height of the camera $(1.35 \mathrm{~m})$ above the ground

- Muscle mechanical analysis camera (2) and videography area $(17.90 \mathrm{~m})$ and camera height $(1.40$ $\mathrm{m})$ above the ground .

- Drawing scale has been developed with 5 meters length.

- Some colleagues from faculty members worked as assistants .

IV- Main study

1- Videography area preparation and player preparation for videography

- Videography place prepared as per pilot study results, and carried out at 11 am in track and field competition land at Faculty of Physical Education for Girls, Alexandria University, player (research sample) was prepared by fixing electrodes (EMG) consisting of three poles for each muscle put on muscle's half, taking into account cleaning skin by ethyl alcohol, as well as put adhesive labels on anatomical points of player body joints . 
- Explained purpose of electrophoresis analysis to player (research sample) and measurement method so as to remove fear factor of electrical connections of the device, as well as to explain the proposed exercises for the player and the steps that will pass with surrounding imaging performance to be a sense as if it were in an actual match. and has the imaging process synchronous between a (EMG) and biomechanics videography analysis, working muscles have been identified based on anatomical analysis by dividing the movement to major phases determining joints that share in motion performance, determine the active muscle as well as from previous studies : Jarmo et al (2000), study Walker. S, et al (2011) study Kakeinana W. \& Suzuki S. (2001)

Table (2)

Lower limp working muscles of each of (hops, step and jump) for the triple jump competition

\begin{tabular}{|c|l|}
\hline$\square$ & 1R:Gluteus maximus muscle \\
\hline$\square$ & 2R:Quadriceps femoris muscle - rectus femoris \\
\hline$\square$ & 3 L:Gluteus maximus muscle \\
\hline
\end{tabular}

\begin{tabular}{|c|l|}
\hline$\square$ & 4L:Quadriceps femoris muscle - rectus femoris \\
\hline$\square$ & 5R:Quadriceps femoris muscle - vastus lateralis \\
\hline$\square$ & 6R:Quadriceps femoris muscle - vastus medialis \\
\hline$\square$ & 7 R:Gastrocnemius muscle - lateral part \\
\hline$\square$ & 8 R:Tibialis anterior muscle \\
\hline$\square$ & 9 L:Quadriceps femoris muscle - vastus lateralis \\
\hline$\square$ & 10 L:Quadriceps femoris muscle - vastus medialis \\
\hline$\square$ & 11 L:Gastrocnemius muscle - lateral part \\
\hline- & 12 L:Tibialis anterior muscle \\
\hline
\end{tabular}

Player (research sample) was filmed during her performance of triple jump, as well as ead proposed exercises (training modules for each of hop, step and jump), which have been identified from references and previous studies to fit the training, It has been taken into account that proposed exercises should match triple jump movement path, also takes into account that the land to be of tartans even for player's safety and security and final number of exercises were final five which is :

First exercise: medical ball + medical ball $+30 \mathrm{~cm}$ height barrier

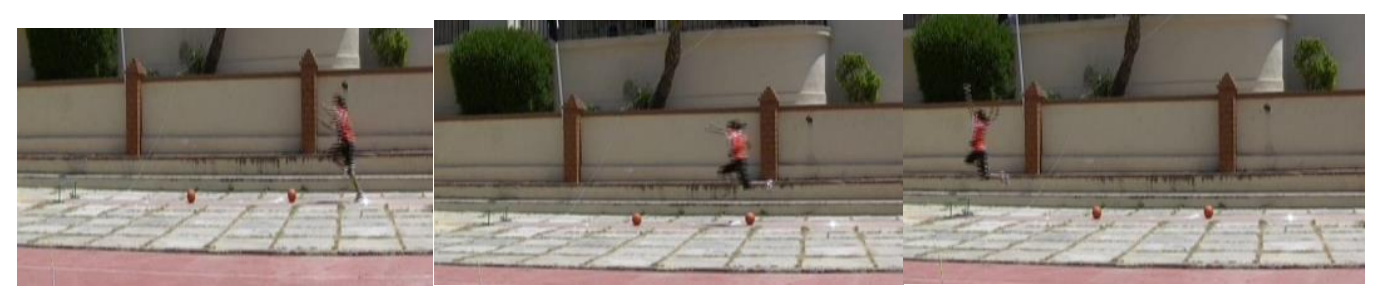

Second Exercise: medical ball $+30 \mathrm{~cm}$ height barrier $+40 \mathrm{~cm}$ height barrier .
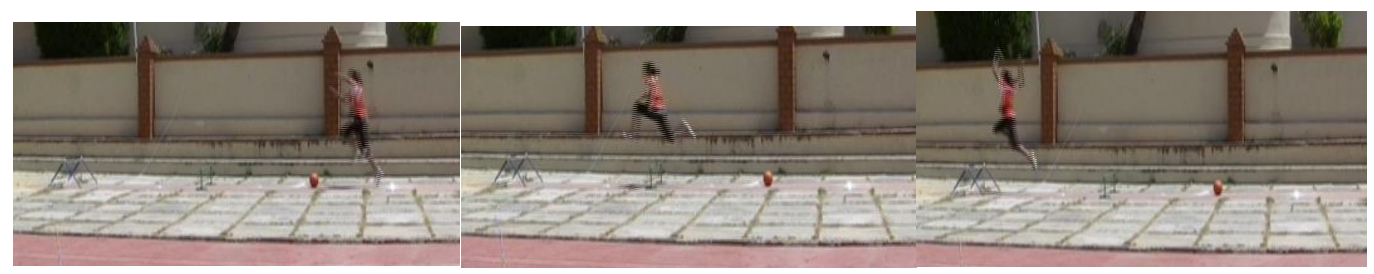

Third Exercise: three $30 \mathrm{~cm}$. height barriers
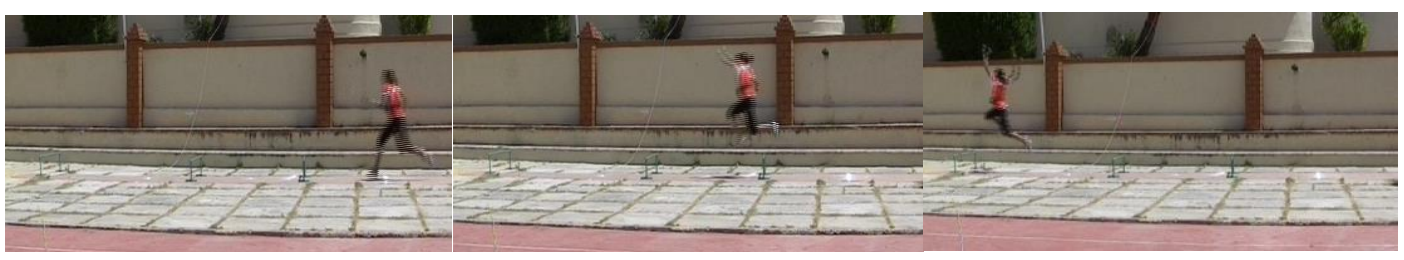

Fourth Exercise: $17 \mathrm{~cm}$ height stop $+40 \mathrm{~cm}$ height barrier $+17 \mathrm{~cm}$ height stop .

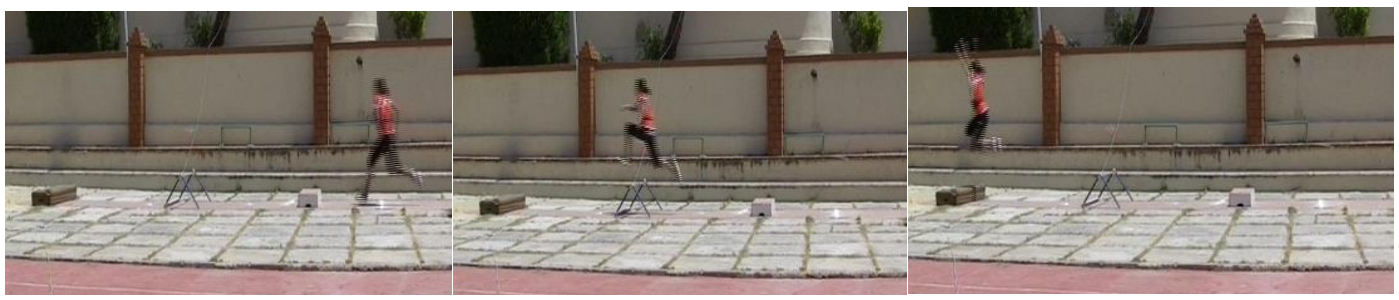

Fifth exercise: $17 \mathrm{~cm}$ height stop + empty + jump ladder . 


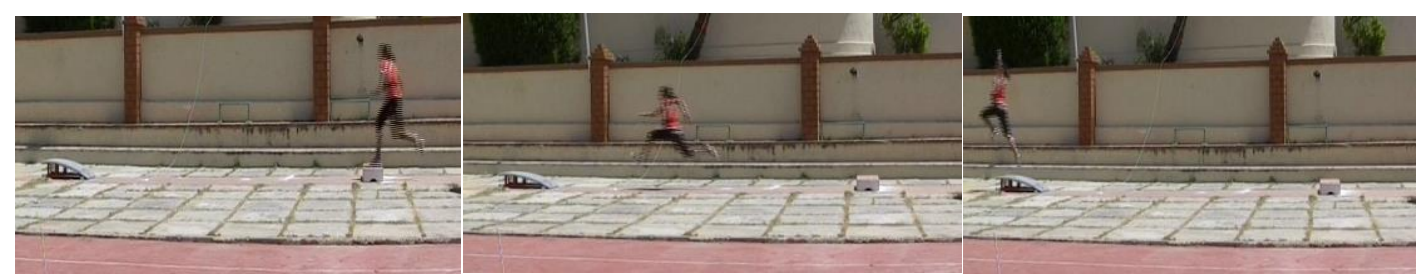

The player has three performance attempts after a good warm-up, the best attempt has been chosen to motor and muscle analyze, researcher has taken into account not straining the player until the results of the analysis is not affected as a result of muscular fatigue .

\section{2- Second: electrical activity and kinetic analysis :}

\section{VI - Results and discussion:}

\section{1- First query results}

\section{Figure (1)}

illustrates the takeoff stage of each of (hop, step and jump) for the triple jump competition
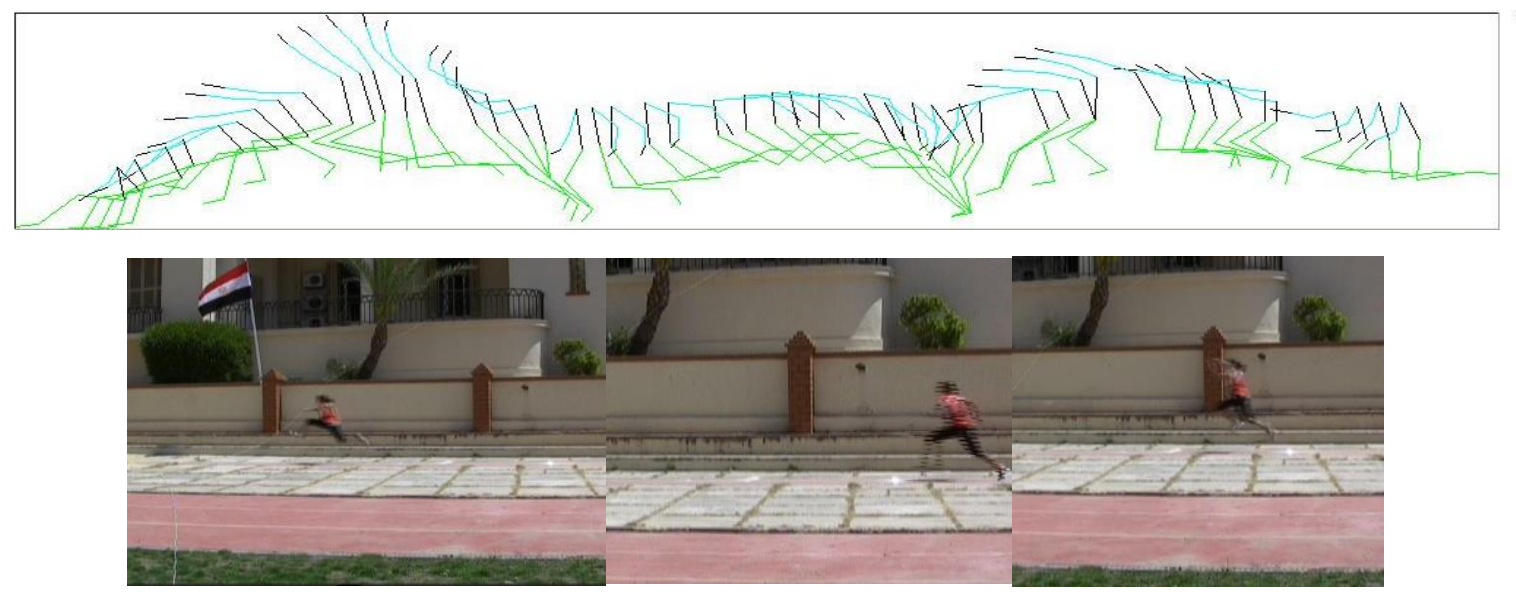

Hop in the main attempt step in main attempt jump in main attempt
Electrical analyzing process as well as the kinematic analysis carried out at mechanical lab, Faculty of Physical Education for Girls, Alexandria University, prepared for motor analysis to extract all variables associated with the research, which has been exported automatically to Excel (MS office program), as well as downloading filmed attempts from camera to computer for kinetic analysis to extract data required . 
Table (3)

Maximum contraction and muscle contribution rates in takeoff stage of (hop, step and jump) for the triple jump competition

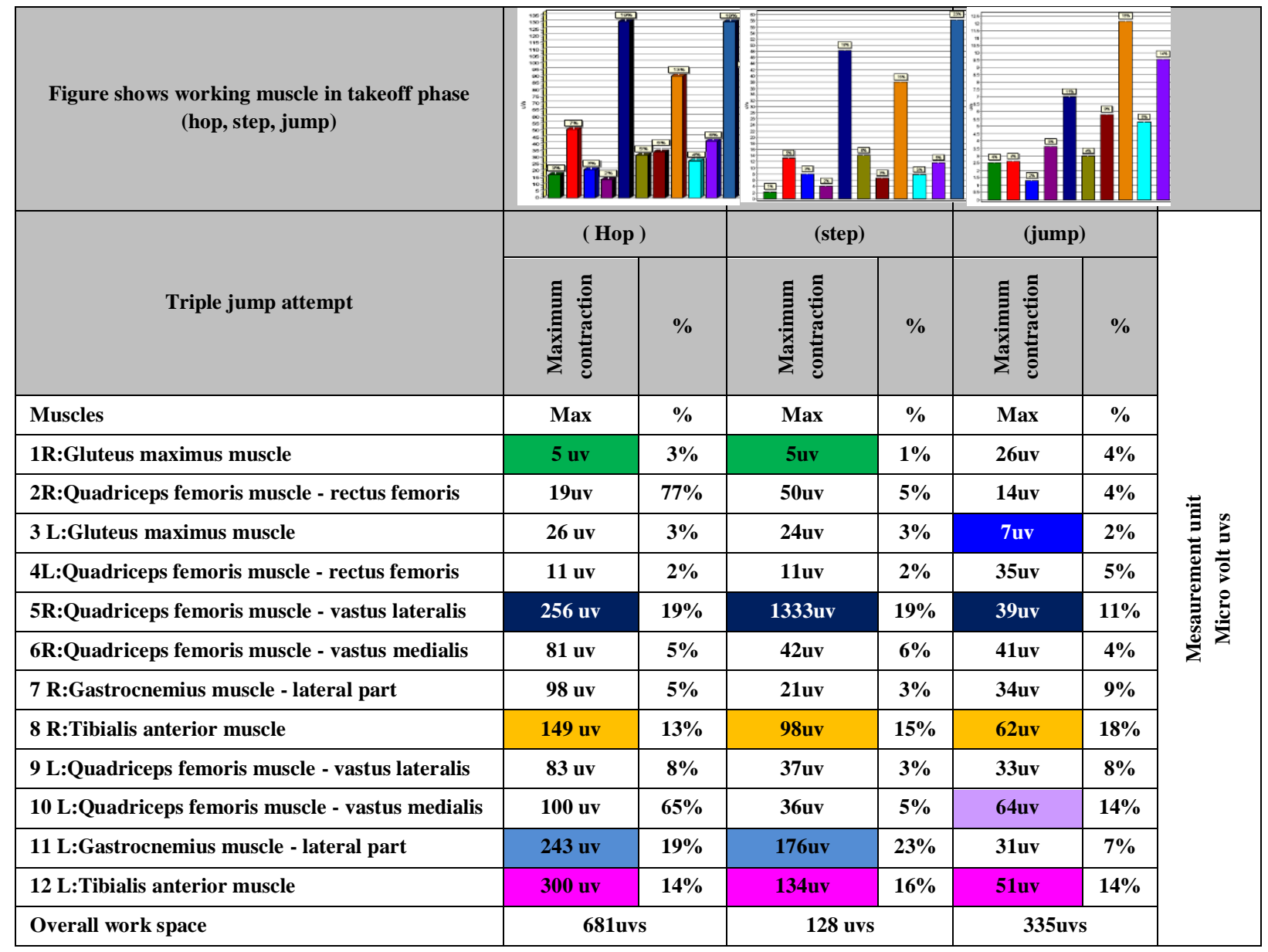

Table No. (3) show that the highest contribution percentage of muscles working in (Hops) was the Quadriceps femoris muscle - vastus lateralis where it reached the maximum contraction of 256uv (19\%), followed by L:Gastrocnemius muscle - lateral part 243uv (19\%), while the lowest rate was for Gluteus maximus muscle with maximum contraction $5 \mathrm{uv}$ $(3 \%)$.

Sasme table results indicate that highest percentage contribution of muscles working in (Step) were L:Gastrocnemius muscle - lateral part left 171 uv (23\%) followed by 5R:Quadriceps femoris muscle - vastus lateralis 133uv (19\%) while the muscle contribution was working for Gluteus maximus muscle 5uv with rate $(1 \%) \%$.

Same table results shows also that the highest working muscle contribution working in (jump) were R:Tibialis anterior muscle with maximum contraction $62 \mathrm{uv}(18 \%)$ followed by L:Quadriceps femoris muscle - vastus medialis 64uv (14\%); while lowest contribution rate was :Gluteus maximus muscle $7 \mathrm{uv}(2 \%)$.

Results showed that highest electrophoresis values was in step, muscle electrical activity in hop 681uvs uvs, while in step 128 uvs Micro Vault, and in jump 335 uvs .

\section{2- First query discussion:}

Results were discussed based on the results of variables associated with muscle electrical activity analyze of the triple jump competition and specific exercises and compare some of the results of previous studies and references related to the this research matter, and discuss the results according to research queries .

Table (3) results reveal that highest contribution percentage in (hop, and step) was for Quadriceps femoris muscle vastus lateralis then L:Gastrocnemius muscle - lateral part , followed by :Tibialis anterior muscle; while in (jump) were R:Tibialis anterior muscle followed by L:Quadriceps femoris muscle - vastus medialis then L:Tibialis anterior muscle followed by R:Quadriceps femoris muscle - vastus lateralis

And so we find that the high amount of electrical activity of these muscles during takeoff phase demonstrates the importance of training these muscle to contract the joints of takeoff leg, as shown by results of measuring muscles' electrical activity during performance of each of hop, step and jump in triple jump that the highest values of electrophoresis activity was in step, then jump followed by hop. This interpretation is consistent with the principles 
associated with muscle composition and functional nervous system where muscle to contract more forcefully if it is placed in the case of prolonging before the start of the contraction. (Talha Hussain, 1994 :p13)

From the above, we find that the most important muscle are R:Quadriceps femoris muscle - vastus lateralis, $\mathrm{R}$ :Quadriceps femoris muscle - vastus medialis, $\mathrm{R}$ :Gastrocnemius muscle - lateral part, R:Tibialis anterior muscle, L:Tibialis anterior muscle, and R:Quadriceps femoris muscle - rectus femoris and this was confirmed by JARMO et al (2000, p236) study that the most important 3- Second and third queries results muscle is the calf muscles, and Quadriceps femoris muscle muscles and hip flexor, which play an important role in pushing (24: 336), Walker and others Walker et al (2011, p262-269) proofed that the most important muscle are R:Quadriceps femoris muscle - vastus lateralis, 6R:Quadriceps femoris muscle - vastus mediali and 2R:Quadriceps femoris muscle - rectus femoris (26 :262269) and one of the most important results of W. Kakihana \& S. Suzuki (2001) study the confirmation that these muscles that give greater impulse force at takeoff moment and this answer first query.

Table (4)

Maximum contraction and muscle contribution rates in takeoff stage of (hop, step and jump) for first exercise

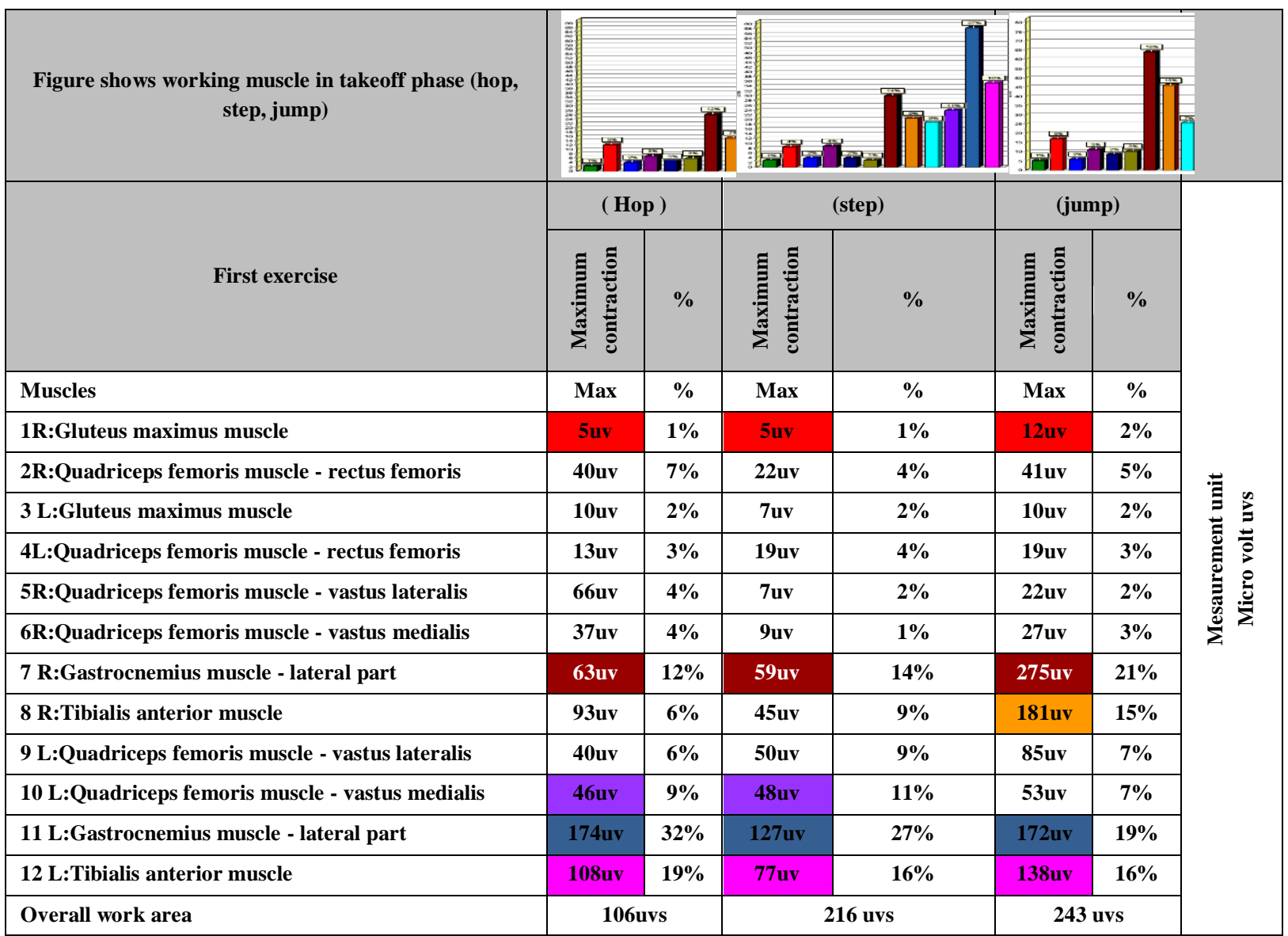

Table (4), indicates that the maximum contraction and contribution rates for working muscles for (Hops) were for L:Gastrocnemius muscle - lateral part with maximum contraction $174 \mathrm{uv}(32 \%)$, followed by L:Tibialis anterior muscle 108uv (19\%), while the lowest rates of contribution to the muscles working was R:Gluteus maximus muscle $5 \mathrm{uv}$ $(1 \%)$,

Same table results also indicate that highest contribution for working muscles in (Step) were L:Gastrocnemius muscle lateral part with maximum contraction 127uv (27\%) followed by L:Tibialis anterior muscle $77 \mathrm{uv}(16 \%)$, while the lowest muscle contribution were R:Gluteus maximus muscle 5 uv (1\%).

Table results also indicates that highest contribution percentage for working muscles in (Jump) were R:Gastrocnemius muscle - lateral part with maximum contraction $275 \mathrm{uv}(21 \%)$ followed by L:Gastrocnemius muscle - lateral part 172uv (19\%), while the working muscles lower contribution rates were Quadriceps femoris muscle - rectus femoris where 10uv (2\%).

Results indicate that during first exercise highest values of electrophoresis activity was in the jump, with muscle 
electrical activity values of 243 uvs, while values were in step 216 uvs, and in hop $106 u v s$.

Table (5)

Maximum contraction and muscle contribution rates in takeoff stage of

(hop, step and jump) for second exercise

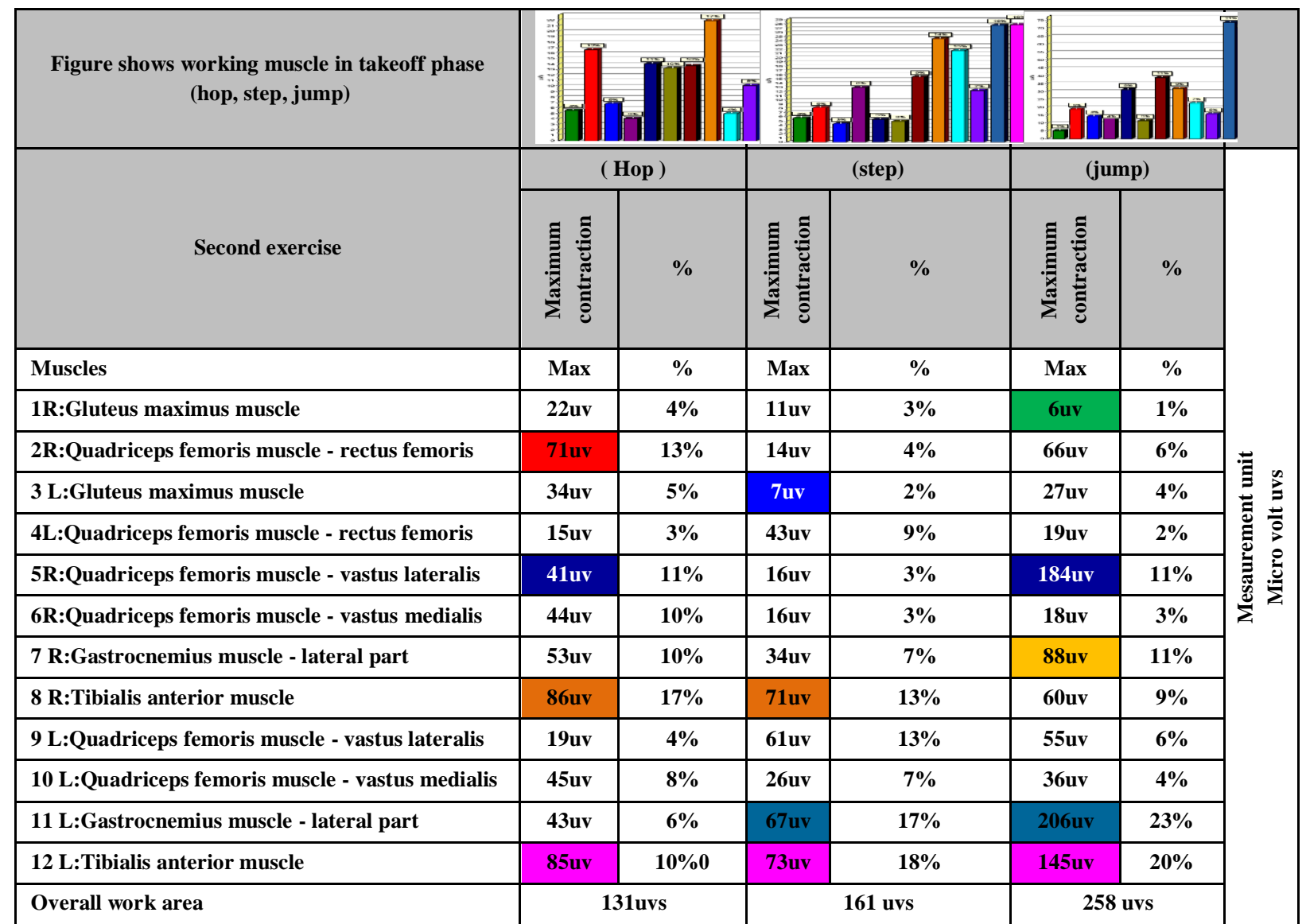

Table No. 5 results reveal that working muscles highest contribution percentage in (Hop) were R:Tibialis anterior muscle where the maximum contraction of her 86uv (17\%), followed by Quadriceps femoris muscle - rectus femoris 71 uv (13\%), while the lowest rates of working muscles contribution was Quadriceps femoris muscle - rectus femoris with maximum contraction $15 \mathrm{uv}(3 \%)$.

Same table also indicates that working muscles highest contribution percentage in (Step) were L:Tibialis anterior muscle where maximum contraction was 73 uv (18\%), followed by L:Gastrocnemius muscle - lateral part $67 \mathrm{uv}(17 \%)$, while working muscles lower contribution rate was Gluteus maximus muscle with maximum contraction 11 uv $(3 \%)$.
Same results also indicate that working muscles highest contribution percentage in (jump) were L:Gastrocnemius muscle - lateral part with maximum contraction 206uv (23\%) followed by L:Tibialis anterior muscle 145uv (20\%), while lower contribution rate was R:Quadriceps femoris muscle - rectus femoris with maximum contraction 6uv $(1 \%)$.

The electrical activity results during second exercise performance show that highest electrophoresis activity value was in jump with 258 uvs Micro Vault, while of electrical activity value in step were 161 uvs Micro Vault, and in hop 131uvs the Micro Vault. 
Table (6)

Maximum contraction and muscle contribution rates in takeoff stage of (hop, step and jump) for third exercise

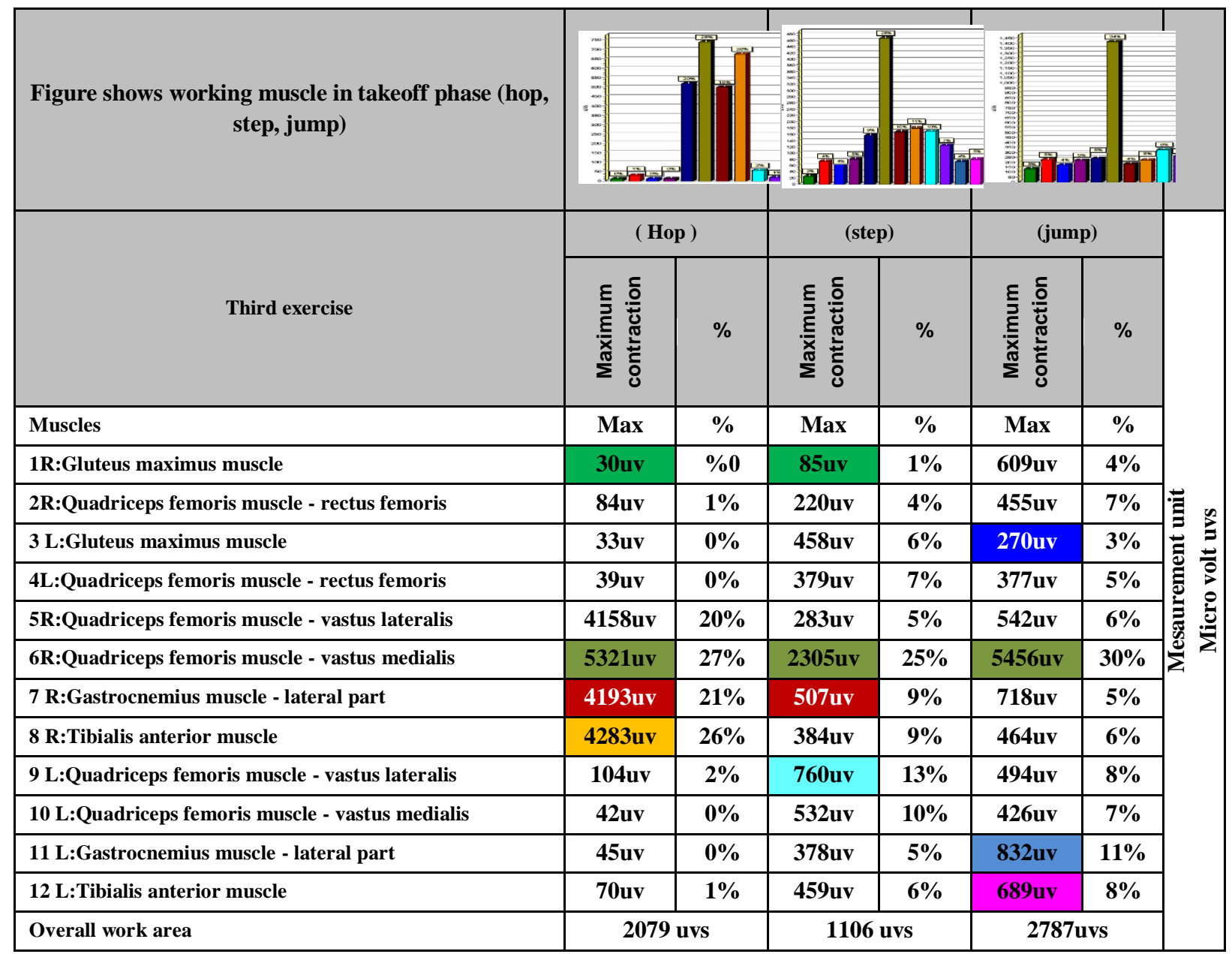

Table (6) results reveal that working muscles highest contribution percentage in (Hop) were R:Quadriceps femoris muscle - vastus with maximum contraction 5321uv (27\%), followed by R:Tibialis anterior muscle maximum contraction 4283uv (26\%), while the lowest working muscles contribution rate were Gluteus maximus muscle with maximum contraction 30uv $(0 \%)$.

Same table results also indicate that working muscles highest contribution percentage in (Step) were Quadriceps femoris muscle - vastus medialis with maximum contraction 2305 uv (25\%) followed by L:Quadriceps femoris muscle vastus lateralis $760 \mathrm{uv}(13 \%)$, while working muscles lowest contribution rate were R:Gluteus maximus muscle with maximum contraction $85 \mathrm{uv}(1 \%)$.
Same results also indicate that working muscles highest contribution percentage in (jump) were R:Quadriceps femoris muscle - vastus medialis with maximum contraction 5456uv (30\%), followed by L:Gastrocnemius muscle lateral part $832 \mathrm{uv}(11 \%)$, while working muscles lowest contribution rate were L:Gluteus maximus muscle where with maximum contraction $270 \mathrm{uv}(3 \%)$.

The electrical activity results during third exercise show that highest electrophoresis activity was in jump, reaching muscle activity value of 2787 uvs, while value in hop was 2079 uvs, and in step was 1106 uvs. 
Table (7)

Maximum contraction and muscle contribution rates in takeoff stage of (hop, step and jump) for fourth exercise

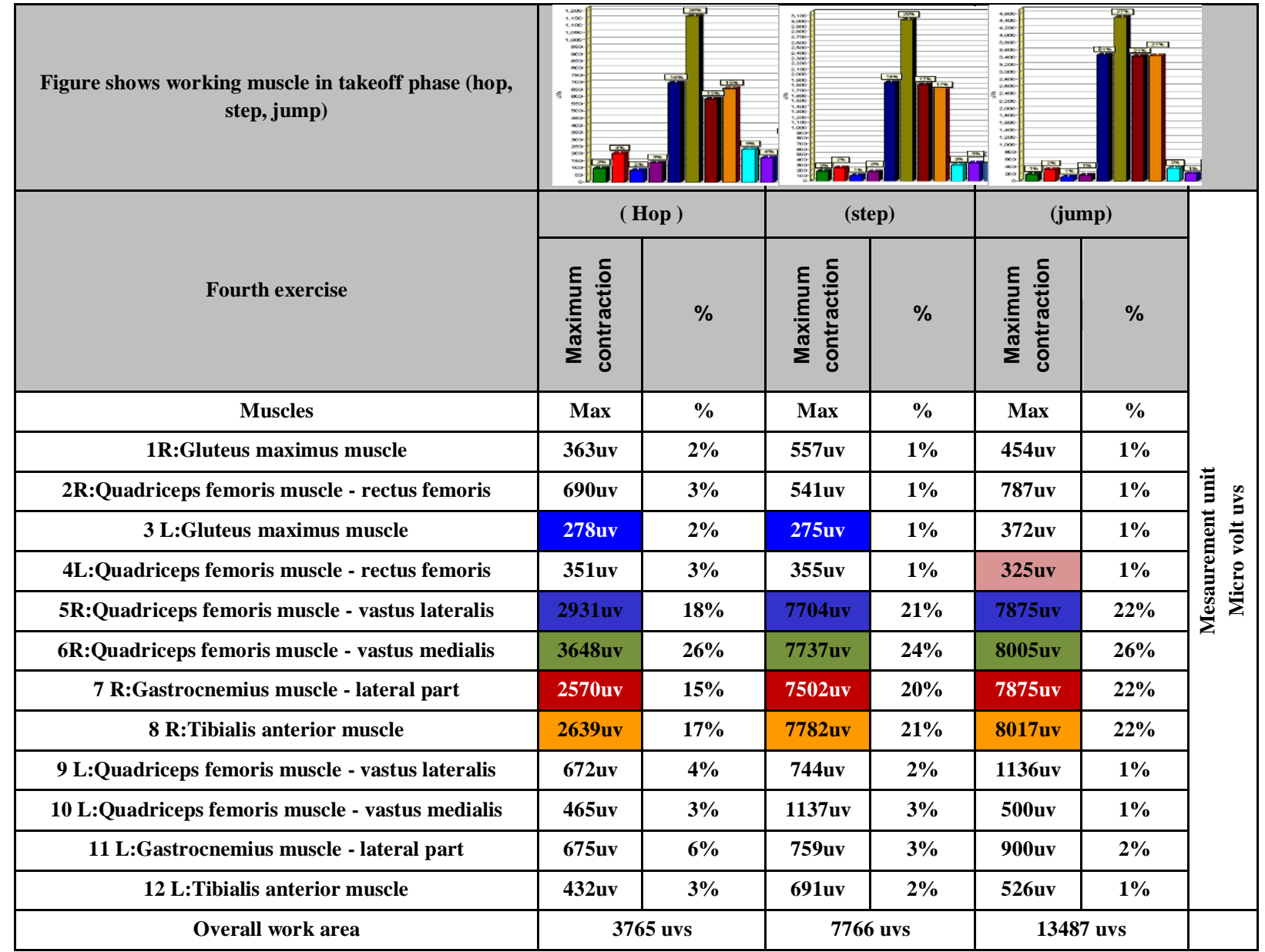

Table (7) results reveal that working muscles highest contribution rates in (Hop) were R:Quadriceps femoris muscle - vastus medialis with maximum contraction $3648 \mathrm{uv}$ (26\%), followed by Quadriceps femoris muscle - vastus lateralis maximum contraction 2931uv (18\%), while working muscles lowest contribution rate were Gluteus maximus muscle with maximum contraction 278uv (2\%).

Same results also indicate that working muscles high contribution rates in (Step) were R:Quadriceps femoris muscle - vastus medialis with maximum contraction $7737 \mathrm{uv}$ (24\%) followed by R:Tibialis anterior muscle 7782uv ( $21 \%$ ), while working muscles lowest contribution were L:Gluteus maximus muscle with maximum contraction 275uv (1\%)
Same results also indicate that working muscles highest contribution percentage in (jump) were R:Quadriceps femoris muscle - vastus medialis with maximum contraction 8005 uv (26\%) followed by R:Tibialis anterior muscle 8017 uv (22\%), while working muscles lowest contribution rates were L:Quadriceps femoris muscle - rectus femoris with maximum contraction $325 \mathrm{uv}(1 \%)$.

Muscles electrical activity results during fourth exercise performance show that the highest electrophoresis activity was in the jump reaching muscle electrical activity of 13487 uvs, while the value in step was 7766uvs, and in hop was 3765uv 
Table (8)

Maximum contraction and muscle contribution rates in takeoff stage of (hop, step and jump) for fifth exercise

\begin{tabular}{|c|c|c|c|c|c|c|c|}
\hline $\begin{array}{l}\text { Figure shows working muscle in takeoff phase (hop, } \\
\text { step, jump) }\end{array}$ & 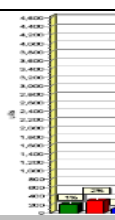 & 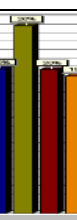 & 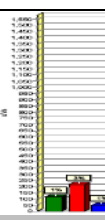 & & 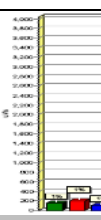 & & \\
\hline \multirow[b]{2}{*}{ Fifth exercise } & \multicolumn{2}{|c|}{ ( Hop ) } & \multicolumn{2}{|c|}{ (step) } & \multicolumn{2}{|c|}{ (jump) } & \multirow{16}{*}{ 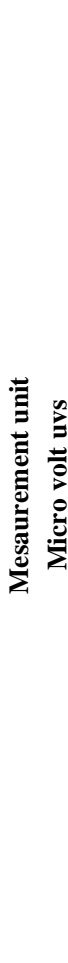 } \\
\hline & 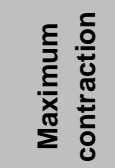 & $\%$ & 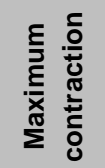 & $\%$ & 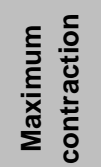 & $\%$ & \\
\hline Muscles & Max & $\%$ & Max & $\%$ & Max & $\%$ & \\
\hline 1R:Gluteus maximus muscle & 479uv & $2 \%$ & 404uv & $1 \%$ & 540uv & $\mathbf{0 \%}$ & \\
\hline 2R:Quadriceps femoris muscle - rectus femoris & 704uv & $3 \%$ & 788uv & $2 \%$ & 237uv & $1 \%$ & \\
\hline 3 L:Gluteus maximus muscle & 302uv & $0 \%$ & 85uv & $\mathbf{0 \%}$ & $377 u v$ & $1 \%$ & \\
\hline 4L:Quadriceps femoris muscle - rectus femoris & 443uv & $1 \%$ & 188uv & $1 \%$ & 616uv & $1 \%$ & \\
\hline 5R:Quadriceps femoris muscle - vastus lateralis & 5101uv & $17 \%$ & $7478 u v$ & $21 \%$ & 7948uv & $26 \%$ & \\
\hline 6R:Quadriceps femoris muscle - vastus medialis & 8004uv & $\mathbf{3 3} \%$ & $7253 u v$ & $20 \%$ & 7829uv & $21 \%$ & \\
\hline 7 R:Gastrocnemius muscle - lateral part & $5157 u v$ & $16 \%$ & $7200 u v$ & $20 \%$ & 7866uv & $21 \%$ & \\
\hline 8 R:Tibialis anterior muscle & 4978uv & $15 \%$ & 7539uv & $20 \%$ & 8017uv & $22 \%$ & \\
\hline 9 L:Quadriceps femoris muscle - vastus lateralis & 656uv & $3 \%$ & 498uv & $1 \%$ & 1302uv & $2 \%$ & \\
\hline $10 \mathrm{~L}: Q u a d r i c e p s$ femoris muscle - vastus medialis & $735 u v$ & $2 \%$ & 426uv & $1 \%$ & 1019uv & $2 \%$ & \\
\hline 11 L:Gastrocnemius muscle - lateral part & 2205uv & $6 \%$ & 3948uv & $12 \%$ & 4091uv & $7 \%$ & \\
\hline 12 L:Tibialis anterior muscle & 629uv & $1 \%$ & $217 u v$ & $1 \%$ & 863uv & $1 \%$ & \\
\hline Overall work area & \multicolumn{2}{|c|}{6091 uvs } & \multicolumn{2}{|c|}{5387 uvs } & \multicolumn{2}{|c|}{16850 uvs } & \\
\hline
\end{tabular}

Table (8) results reveal that working muscles highest contribution rates in (Hop) was the muscle were R:Quadriceps femoris muscle - vastus medialis with maximum contraction 8004uv ( $33 \%)$, followed by $\mathrm{R}:$ Quadriceps femoris muscle - vastus lateralis $5101 \mathrm{uv}$ $(17 \%)$, while working muscles lowest contribution rate were L:Gluteus maximus muscle with maximum contraction $302 u v$ (of 0\%).

Same results also indicate that working muscles highest contribution percentage in (Step) were Quadriceps femoris muscle - vastus lateralis with maximum contraction 7478 uv (21\%) followed R:Tibialis anterior muscle 7539 uv (20\%), while working muscles lowest contribution rate was for L:Gluteus maximus muscle with maximum contraction $85 \mathrm{uv}$ $(0 \%)$.

Same results also indicate that that working muscles highest contribution percentage in (jump) were R:Tibialis anterior muscle with maximum contraction 8017 uv (22\%), followed by R:Quadriceps femoris muscle - vastus lateralis 7948uv(21\%), While working muscles lower contribution rate was for R:Quadriceps femoris muscle - rectus femoris with maximum contraction $237 \mathrm{uv}(1 \%)$,
Muscles electrical activity results during fifth exercise performance show that the highest electrical activity value was in jump 16850 uvs Micro Vault, while the value in hop was 6091 uvs Micro Vault, and in step 5387uvs the Micro Vault.

\section{3- Second and third queries discussion: -}

We note through muscle electrical activity analysis that the most important working muscles in (1st and 2 nd exercises) are R:Quadriceps femoris muscle - vastus lateralis, $\mathrm{R}$ :Quadriceps femoris muscle - vastus medialis,

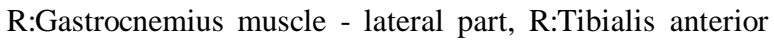
muscle, and R:Quadriceps femoris muscle - rectus femoris and are the same working muscles in triple jump and almost with the same values of muscles maximum contraction values. While in $\left(3^{\text {rd }}, 4^{\text {th }}\right.$, and $\left.5^{\text {th }}\right)$ exercises the most important working muscles are R:Quadriceps femoris muscle - vastus lateralis, R:Quadriceps femoris muscle vastus medialis, R:Gastrocnemius muscle - lateral part and R:Tibialis anterior muscle. Maximum contraction value is significantly higher than those in $1^{\text {st }}$ and $2^{\text {nd }}$ exercises; this may be due to higher tools used used in $3^{\text {rd }}, 4^{\text {th }}$ and $5^{\text {th }}$ exercises, this led to an increase in the burden on muscles, making the free leg movement more strongly as a result of 
increased height; as the work requires free leg withdrawal backward and takeoff leg forward and upward and then stretching it forward to touch the land

Mohamed Hassan Allawi (1990, p294) and Essam AbdelKhalek (1994, p18) confirmed that exercises similar to skills performance nature are similar in motor composition with movements performed by player within sports competition in terms of power, speed, force time path, muscle work direction with movements performed, i.e. featured by dynamic match between its path and motor skill technique path using the same working muscle groups in the skill itself. Bastawisy Ahmed (1997, p319) also confirms that to develop triple jump; performance approach speed should be reached to highest level possible, improving takeoff level for both feet, and enjance motor coordination between the three jumps.

Mohamed Shawky, Amr Allah Ahmad (2002) results confirmed that using similar movements led to an improvement in vertical jump level due to using directed exercises and the same working muscle groups. Also Casey
Wilson et al (2009, p277-282) which studied kinetic models for triple jump exercises emphasized that muscles and physical requirements in exercises should be similar to those in triple jump competition.

Electrical activity measuring results during hop, step and jump performance, reveal that electrical activity values were higher in $\left(3^{\text {rd }}, 4^{\text {th }}\right.$, and $\left.5^{\text {th }}\right)$ and this is due to that as tools high is simple as the muscles overall work area is less and vice versa. This is what we observe in the $\left(1^{\text {st }}\right.$, and $\left.2^{\text {nd }}\right)$ exercises. If the height increased overall work area increased and other muscles contribute with larger percentage as in $\left(3^{\text {rd }}, 4^{\text {th }}\right.$, and $\left.5^{\text {th }}\right)$ exercises and so we find that whenever tools height is simple same muscles works as per triple jump muscles arrangement. This answer second and third queries.

Tables $(4,5,6,7,8)$ that indicates that the lowest contribution percentage was for R:Quadriceps femoris muscle - rectus femoris, and L:Gluteus maximus muscle with very low values, which advocated the need to subdue these muscles to training program for motor speed of response development to activate basic motor units.

\section{4- Fourth hypothesis results:}

Table (9)

Velocity indicator value for lower limp center of gravity (COG) for takeoff phase (hop, step, and jump) for triple jump competition

\begin{tabular}{|c|c|c|c|c|c|c|c|c|c|}
\hline Take of moment & \multicolumn{3}{|c|}{ Hop in triple jump } & \multicolumn{3}{|c|}{ Step in triple jump } & \multicolumn{3}{|c|}{ Jump in triple jump } \\
\hline & $\begin{array}{c}\text { Horizontal } \\
\text { velocity }\end{array}$ & $\begin{array}{l}\text { Vertical } \\
\text { Velocity }\end{array}$ & $\begin{array}{l}\text { Velocity } \\
\text { resultant }\end{array}$ & $\begin{array}{c}\text { Horizontal } \\
\text { velocity }\end{array}$ & $\begin{array}{l}\text { Vertical } \\
\text { Velocity }\end{array}$ & $\begin{array}{l}\text { Velocity } \\
\text { resultant }\end{array}$ & $\begin{array}{c}\text { Horizontal } \\
\text { velocity }\end{array}$ & $\begin{array}{l}\text { Vertical } \\
\text { Velocity }\end{array}$ & $\begin{array}{r}\text { Velocity } \\
\text { resultant }\end{array}$ \\
\hline & $\mathrm{Vx}[\mathrm{cm} / \mathrm{s}]$ & $\mathrm{Vy}[\mathrm{cm} / \mathrm{s}]$ & $\mathrm{V}[\mathrm{cm} / \mathbf{s}]$ & $\mathrm{Vx}[\mathrm{cm} / \mathrm{s}]$ & $\mathrm{Vy}[\mathrm{cm} / \mathrm{s}]$ & $\mathrm{V}[\mathrm{cm} / \mathbf{s}]$ & $\mathrm{Vx}[\mathrm{cm} / \mathrm{s}]$ & $\mathrm{Vy}[\mathrm{cm} / \mathrm{s}]$ & $\mathrm{V}[\mathrm{cm} / \mathrm{s}]$ \\
\hline \multirow{2}{*}{$\begin{array}{c}\text { Frames } \\
\text { Variables }\end{array}$} & \multicolumn{3}{|c|}{ Time $(0.033: 0.233)$} & \multicolumn{3}{|c|}{ Time (0.6: $0.733 \odot)$} & \multicolumn{3}{|c|}{ Time (1:12) } \\
\hline & \multicolumn{3}{|c|}{ Frames (1-8) } & \multicolumn{3}{|c|}{ Frames 19-23 } & \multicolumn{3}{|c|}{ Frames 31-37 } \\
\hline Body COG & -560.772 & 124.165 & -575.075 & -556.127 & 102.107 & -534.863 & -459.216 & 120.767 & -396.923 \\
\hline Thigh COG & -573.432 & 132.291 & -538.631 & -524.349 & 85.222 & -506.66 & -555.84 & 78.449 & -399.118 \\
\hline Shank COG & -811.813 & 123.889 & -791.587 & -534.201 & 210.654 & -522.161 & -665.75 & 138.464 & -436.724 \\
\hline Foot COG & -1050.9 & -158.612 & -1050.15 & -511.33 & 366.865 & -580.465 & -742.234 & 249.235 & -632.774 \\
\hline
\end{tabular}

Table (9) results reveal that highest rate of Body COG was in hop followed by step, the lowest rate in jump, also velocity resultant for lower limb was at highest rate in hop and lowest rate in the jump, and resultant speed for step were between hop and jump except for foot where resultant speed in step is less than in the jump. 
Figure (2)

Velocity indicator value for lower limp center of gravity (COG) for takeoff phase (hop, step, and jump) for triple jump competition

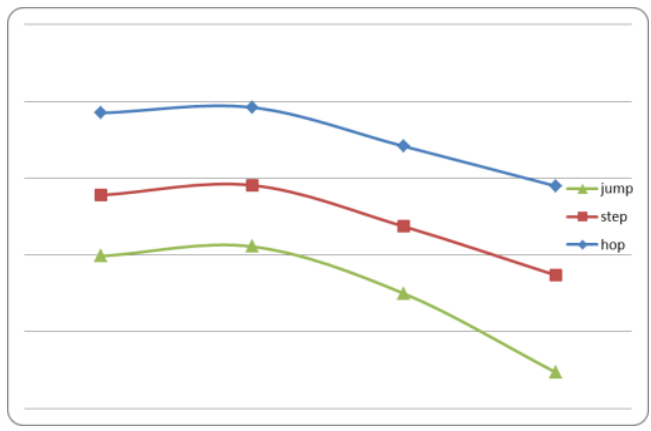

Table (10)

Force indicator value for lower limp center of gravity (COG) for takeoff phase (hop, step, and jump) for triple jump competition

\begin{tabular}{|c|c|c|c|c|c|c|c|c|c|}
\hline Take of moment & \multicolumn{3}{|c|}{ Hop in triple jump } & \multicolumn{3}{|c|}{ Step in triple jump } & \multicolumn{3}{|c|}{ Jump in triple jump } \\
\hline & $\begin{array}{c}\text { Horizontal } \\
\text { force }\end{array}$ & $\begin{array}{c}\text { Vertical } \\
\text { Force }\end{array}$ & $\begin{array}{c}\text { Force } \\
\text { resultant }\end{array}$ & $\begin{array}{c}\text { Horizontal } \\
\text { force }\end{array}$ & $\begin{array}{c}\text { Vertical } \\
\text { Force }\end{array}$ & $\begin{array}{c}\text { Force } \\
\text { resultant }\end{array}$ & $\begin{array}{c}\text { Horizontal } \\
\text { force }\end{array}$ & $\begin{array}{l}\text { Vertical } \\
\text { Force }\end{array}$ & $\begin{array}{c}\text { Force } \\
\text { resultant }\end{array}$ \\
\hline & Force-x[N] & $\begin{array}{c}\text { Force- } \\
y[N]\end{array}$ & |Force|[N] & Force-x[N] & Force-y[N] & |Force $\mid[\mathbf{N}]$ & Force-x[N] & Force-y[N] & $\mid$ Force $\mid[\mathbf{N}]$ \\
\hline \multirow{2}{*}{$\begin{array}{c}\text { Frames } \\
\text { Variables }\end{array}$} & \multicolumn{3}{|c|}{ Time (0.033 : 0.233$)$} & \multicolumn{3}{|c|}{ Time (0.6: $0.733(;)$} & \multicolumn{3}{|c|}{ Time (1:12) } \\
\hline & \multicolumn{3}{|c|}{ Frames (1-8) } & \multicolumn{3}{|c|}{ Frames 19-23 } & \multicolumn{3}{|c|}{ Frames 31-37 } \\
\hline Body COG & -880.425 & -296.489 & 886.06 & -598.147 & -452.629 & 662.229 & -522.378 & -452.719 & 524.016 \\
\hline Thigh COG & -396.133 & -154.822 & 396.314 & -310.561 & -195.574 & 326.178 & -307.804 & $\mathbf{5 3 . 8 5 7}$ & 307.959 \\
\hline Shank COG & -231.637 & -48.025 & 231.909 & -137.359 & -112.87 & 162.761 & -163.874 & 67.062 & 185.57 \\
\hline Foot COG & -103.701 & -23.264 & 105.507 & -37.693 & -53.453 & 54.643 & 58.191 & 42.306 & 67.544 \\
\hline
\end{tabular}

Table (10) results reveal that force resultant for Body COG wad at highest rate in hop followed by step and was the lowest rate in jump, results also shows that lower limp force resultant were at highest rate in hop and at lowest rate in step and values og step were between hop and jump

Figure (3)

Force indicator value for lower limp center of gravity (COG) for takeoff phase (hop, step, and jump) for triple jump competition

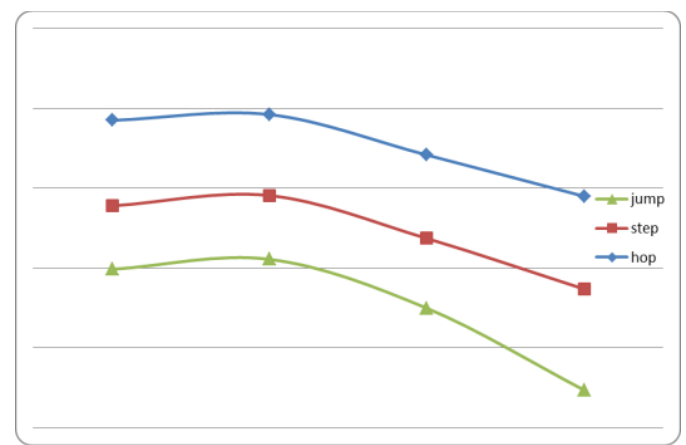


Table (11)

Impulse indicator value for lower limp center of gravity (COG) for takeoff phase (hop, step, and jump) for triple jump competition

\begin{tabular}{|c|c|c|c|c|c|c|c|c|c|}
\hline \multirow{3}{*}{$\begin{array}{l}\text { Take of } \\
\text { moment }\end{array}$} & \multicolumn{3}{|c|}{ Hop in triple jump } & \multicolumn{3}{|c|}{ Step in triple jump } & \multicolumn{3}{|c|}{ Jump in triple jump } \\
\hline & $\begin{array}{l}\text { Horizontal } \\
\text { impulse }\end{array}$ & $\begin{array}{l}\text { Vertical } \\
\text { Impulse }\end{array}$ & $\begin{array}{l}\text { Impulse } \\
\text { resultant }\end{array}$ & $\begin{array}{c}\text { Horizontal } \\
\text { impulse }\end{array}$ & $\begin{array}{l}\text { Vertical } \\
\text { Impulse }\end{array}$ & $\begin{array}{l}\text { Impulse } \\
\text { resultant }\end{array}$ & $\begin{array}{l}\text { Horizontal } \\
\text { impulse }\end{array}$ & $\begin{array}{l}\text { Vertical } \\
\text { Impulse }\end{array}$ & $\begin{array}{l}\text { Impulse } \\
\text { resultant }\end{array}$ \\
\hline & $\begin{array}{c}\text { Impulse-x } \\
{[\mathrm{N} / \mathrm{sec}]} \\
\end{array}$ & $\begin{array}{c}\text { Impulse-y } \\
\text { [N/sec] }\end{array}$ & $\begin{array}{c}\text { Impulse| } \\
{[\mathrm{N} / \mathrm{sec}]} \\
\end{array}$ & $\begin{array}{c}\text { Impulse-x } \\
{[\mathrm{N} / \mathrm{sec}]} \\
\end{array}$ & $\begin{array}{c}\text { Impulse-y } \\
\text { [N/sec] }\end{array}$ & $\begin{array}{c}\text { Impulse } \\
\text { |[N/sec] } \\
\end{array}$ & $\begin{array}{c}\text { Impulse-x } \\
\text { [N/sec] } \\
\end{array}$ & $\begin{array}{c}\text { Impulse-y } \\
{[\mathrm{N} / \mathrm{sec}]} \\
\end{array}$ & $\begin{array}{c}\text { Impulse } \mid \\
{[\mathrm{N} / \mathrm{sec}]}\end{array}$ \\
\hline \multirow{2}{*}{$\begin{array}{c}\text { Frames } \\
\text { Variables }\end{array}$} & \multicolumn{3}{|c|}{ Time $(0.033: 0.233)$} & \multicolumn{3}{|c|}{ Time $(0.6: 0.733 \odot)$} & \multicolumn{3}{|c|}{ Time (1:12) } \\
\hline & \multicolumn{3}{|c|}{ Frames (1-8) } & \multicolumn{3}{|c|}{ Frames 19-23 } & \multicolumn{3}{|c|}{ Frames 31-37 } \\
\hline Body COG & -156.905 & 32.576 & 157.318 & -145.907 & 26.789 & 147.977 & -130.507 & 31.685 & 132.667 \\
\hline Thigh COG & -61.35 & 14.153 & 62.446 & -51.346 & 9.118 & 54.096 & -59.468 & 8.393 & 60.057 \\
\hline Shank COG & -29.243 & 4.463 & 29.341 & -19.243 & 7.588 & 22.298 & -23.982 & 4.988 & 24.452 \\
\hline Foot COG & -11.252 & -1.698 & 11.379 & -0.893 & 3.928 & 5.862 & -7.947 & 2.669 & 6.729 \\
\hline
\end{tabular}

Table (11) results reveal that impulse resultant for Body COG were at highest rate in hop followed by step and lower rate in jump, results also shows impulse resultant for lower limb COG party were at higher rate in hop, lower in step, and jump values were between hop and step

Figure (4)

Impulse indicator value for lower limp center of gravity (COG) for takeoff phase (hop, step, and jump) for triple jump competition

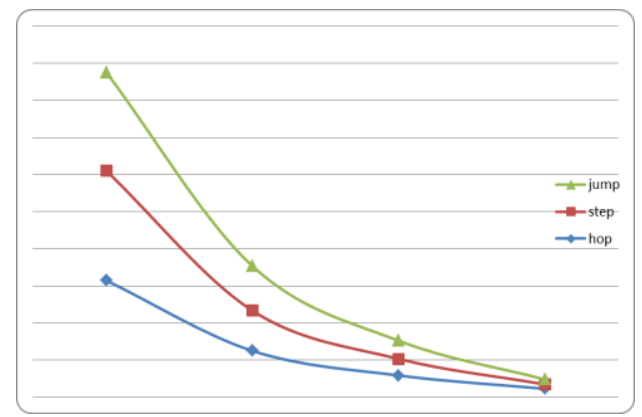

\section{5- Fourth hypothesis discussion:}

Table (10) results indicates that muscles involved in hop, step, and jump, are the same muscles but in different values for maximum contraction. At the same time we note that velocity resultant is lower in step and jump than hop, which is due to that maximum muscles activity affect velocity level. It also noted that there is negative correlation between horizontal and vertical velocities. Where Body COG ate takeoff phase in hop horizontal velocity was $-305.03 \mathrm{~cm} / \mathrm{s}$, and vertical velocity was $124.165 \mathrm{~cm} / \mathrm{s}$, step there was an increase in horizontal velocity to -349.027 offset by a decrease to $102.107 \mathrm{~cm} / \mathrm{s}$, and then horizontal velocity decreased in jump and reached 300.075 - cm / s offset by increase in vertical velocity to $120.767 \mathrm{~cm} / \mathrm{s}$.

This result is consistent with the James.G.Hay, and Peng Yu Bing (1996, p1283-1289) mentioned that the greater profit in the vertical velocity the greater loss in horizontal velocity also found that the loss in horizontal velocity is large in impulse phase and there is a positive linear relationship with an vertical velocity increase during impulse itself
These findings are consistent with Wehbe Alwan Hassoun and Osama Ahmed Hussein (2009) study which proofed that electrical activity of Quadriceps femoris muscle - rectus femoris is an evidence of standing angle increase, as well as that horizontal velocity decreased at the beginning of takeoff moment and then increased at the end of the phase, and these results are consistent with Fukashiro \& Miyashita (1981) study results, where there was decreased horizontal velocity during the first half of each take-off and increased during the second half, also Abdul Rahman Abdul Hamid Zahir (2000, p35) mentioned that increase the vertical composite correlate directly with decrease in horizontal composite to address jump flight range.

Al-Kilani MA, Widule CJ (1990, p267-270) argued that horizontal velocity in step stage, as well as vertical velocity in hop and step affect jump total distance. This is confirmed by Bastawisy Ahmad $(1997,325)$ that takeoff period in step is larger than in hops (5: 325). Qassim Hassan (1999) in the opinion that horizontal velocity in the third jump is very important and velocity loss should be fixed during this hump 
Table (11) results reveals that force resultant was less in step and jump than hops; this is due to that muscles maximum activity affect force of (hip, leg and foot). These results agree with Fukashiro \& Miyashita (1981, 233-237), where they reached that the player must make the horizontal force amounted of 3.6 to 4.4 times of his weight each takeoff time - These results also agrees with Mohamed Abdel Aal et al (2000 , p166) (2001, p180), Mohamed Shawky and the command of Allah Ahmad (2002, p220) that direction to specialty and using muscle abilities gained from plyometric training programs has shown a positive impact in improving movements similar or origin per share

Impulse resultant were also lower in step and jump than I hop; this is due to that muscles maximum activity affect (hip, leg, foot) level. This is confirmed by Bastawisy Ahmad (1997, p318-319) where he argues strong and rapid impulse with takeoff foot help to complete the movement in the lowest possible time from one hand, and from the other reducing losing velocity gained from approaching.

It is noted that there are 8 frames for takeoff moment in hop, 5 faremes for step and 7 for jump. i.e. hop time and frames are larger than step and jump. This is due to that the aim of hop is performing low flight for long distance while minimizing loss of horizontal velocity, where free leg thigh is swinging to horizontal position and towards takeoff leg forward and not upward with pulling free leg forward and upward then extends to front in preparation to touch the ground. (International Athletic Federation for Amateurs: , p90)

This is confirmed by Bastawisy Ahmad (1997, p235) that the period of takeoff phase is larger in step than hop

Tables (10), (11), (12) show that there are correlations between muscles maximum contraction and speed, power and impulse resultants for all joints under discussion. Therefore coaches must pay attention to develop muscles working in skill direction of performance to save player's effort. Bastawisy Ahmad ( 1997, p318-319) confirms that force and velocity elements play positive and important role in triple jump. Three jumps in a row with different rhythms means a difference in application of mechanical foundations that achievement level, so it should be taken into account to get proper angle, either at the beginning of foot setting, or impulse at takeoff phase, Center of gravity arrive to highest appropriate flight distance, coupled with the most appropriate angle of flight, achieve the greatest possible distance. This answers the fourth query.

\section{Conclusions:}

- Muscles electrical activity analysis of triple jump competition, we find that the most important muscle are Quadriceps femoris muscle - vastus lateralis, Quadriceps femoris muscle - vastus medialis, Gastrocnemius muscle - lateral part, and Tibialis anterior muscle
- Electrical activity measuring results during hop, step and jump performance in triple jump competition reveal that highest activity electrophoresis activity was in step with value of 681uvs Micro Vault, while value for hop was 128 uvs Micro Vault, and for jump was 335 uvs.

- That most important muscles working in $\left(1^{\text {st }}\right.$ and $2^{\text {nd }}$ ) exercises vastus are Quadriceps femoris muscle vastus lateralis, Quadriceps femoris muscle - vastus medialis, Gastrocnemius muscle - lateral part, Tibialis anterior muscle and Quadriceps femoris muscle - rectus femoris which are the same working muscles in triple jump and almost with the same of maximum contraction values. Working muscles in $\left(3^{\text {rd }}, 4^{\text {th }}\right.$ and $\left.5^{\text {th }}\right)$ exercises were Quadriceps femoris muscle - vastus lateralis, Quadriceps femoris muscle - vastus medialis, Gastrocnemius muscle - lateral part, and Tibialis anterior muscle

- One of the most important results that that working muscle in the competition are consistent with characteristics of electrical activity of $\left(1^{\text {st }}\right.$ and $\left.2^{\text {nd }}\right)$ exercises, giving more confidence in muscle strength exercises that rely on specific exercises similar to performance nature.

\section{Recommendations:}

- Coaches should not overstate heights which player trained on as it helps muscles involved in performance to work in high load- in addition to other muscles work with greater proportion than muscle necessary for work.

- Emphasis on " principle of privacy " application that most of focus in training programs to be on muscles most involved in specific muscular work this focus be on muscular contraction nature.

- More interest to be given to develop exercises similar to technical performance in terms of muscle shape and work to develop physical and skill fitness elements while designing training programs.

\section{References}

1. Abdel Moneim Ibrahim Hareedy, Ahmed Saad Eddin Mahmoud (1999) : the development of muscle strength in several knee joint angles and its impact on the achievement of triple jump competition, theories and applications Abu Qir , number (34), University of Alexandria (in Arabic language):.

2. Abdul Rahman Abdul Hamid Zahir (2000) : Jump competitions physiology, book publication center, $1^{\text {st }}$ ed., Cairo. (in Arabi Language)

3. Aboul-Ela Abdel Fattah, Mohamed Sobhy Hassanein(1991) : Athelete physiology and morphology and measurement and evaluation methods, Dar ElFekr Elarabi, $1^{\text {st }}$ ed., Cairo (in Arabi Language) 
4. Ahmed Saad Eddin, Osama Mohammed Abu Tabl (2008): Effectiveness of combining plyometric training and electrophoresis on some muscle strength characteristics and record level in triple jump races, Fourth Regional Conference of International Council for Health, physical education and recreation, sports and dance for the Middle East , Faculty of Physical Education, Abu Qir , Part III, Alexandria University. (in Arabic Language)

5. Al-Kilani MA, Widule CJ(1990):Selected kinematic characteristics of intercollegiate women triple jumpers. . Am J Sports Med. 1990 MayJun;18(3):267-70.

6. Bastawisy Ahmad (1997): track and field competitions , "Education . Technique . Training" , $1^{\text {st }}$ ed. , Dar ElFekr ElArabi, Cairo (in Arabic language)

7. Bing. Y (1999):Horizontal-to-vertical velocity conversion in thetriple jump,Journal of Sports Sciences, The University of Nor th Carolina at Chapel Hill, CB \#7135 Medical School Wing E,Chapel Hill, NC 27599-7135, USA.

8. Cassie.W, Scott.S, oseph .H (2009): Movement coordination patterns in triple jump training drills: Journal of Sports Sciences, Volume 27, Number 3, January 2009 , pp. 277-282(6)

9. Essam Abdel-Khalek (1995): Sports training theories - applications, Dar Elmaaref, Cairo .(in Arabic language)

10. Fukashiro S, Iimoto Y, Kobayashi H, Miyashita M A (2000) biomechanical study of the triple jump. received in revised form 15 July 2000; accepted 13 November 2000 (4):233-7.PubMed

11. International Athletic Federation for Amateurs: ( run - jump - shoot) Scientific Guide to teach first level athletics. (in Arabic language)

12. James.G.Hay, Bing. Yu (1996):Optimum phase ratio in the triple jump Journal of Biomechanics .Volume 29, Issue 10 , Pages 1283-1289, October 1996

13. Jarmo Perttunen, Heikki Kyröl. Inen, Paavo v. Komi and Ari Heinonen (2000): Biomechanical loading in the triple jump, Journal of Sports Sciences, 2000, 18, p363- 370, Accepted 22 February 2000

14. Khairia Ibrahim ELsokry, Mohammed Gaber Briqa (2010): biomechanics basic principles in sport field ( qualitative analysis ), second volume, Dar ELmaaref , Alexandria (in Arabic Language)

15. Mohamed Abdel Aal (2000) : Effect of using plyometric, weightlifting and mixed training methods on dynamic development of muscle 's ability and record achievement level for long jump, theories and applications magazine, Faculty of
Physical Education, Alexandria university, issue ( 39) (in Arabi Language)

16. Mohamed Abdel Aal , Abdel Moneim Ibrahim Hareedy, El Sayed Shehata Ahmed (2001): A comparative study of the impact of using proposed exercises to develop muscles relative strength on high vertical jump, Journal of theories and applications , Faculty of Physical Education in Alexandria , Issue (41). (in Arabic Language)

17. Mohamed Hassan Allawi (1990): Sports training , Dar ELmaaref, Cairo (in Arabic Language).

18. Mohamed Shawky El-Sibai, Amr Allah Ahmed Busatti (2002): Impact of plyometric exercises on explosive power in horizontal and vertical direction and speed in some athletes, theories and applications Abu Qir , number (44), the University of Alexandria (in Arabic language)

19. Osama Mohammed Abu Tabl (1999): plyometric exercises standardization using ability analysis of performance dynamic variables in triple jump competition, unpublished Ph.D. thesis, Faculty of Physical Education for Men, Abu Qir, Alexandria University. (in Arabic Language)

20. Qasim Hassan Hussein ( 1999) : Jump events, Dar ELfekr for publishing and distribution, $1^{\text {st }}$ ed., Jordan. (in Arabic Language)

21. Samir Abbas Omar, Abdel Moneim Ibrahim Hareedy (1987): studying the effect of two methods of plyometric exercises on the relative strength of Lower limb and 6 hops distance and time, Scientific Conference of Sports Sciences Development, Volume V, Faculty of Physical Education , Minia University. (in Arabic language)

22. Talha Hussain Hossam El Din , Mohamed Abdel Rahman (1989): sport kinesiology and kinetic analysis foundations, Dar Elfekr Elaraby, Cairo(in Arabic language)

23. Talha Hussein Hossam El Din (1994): Motor and functional foundations for sports training, Dar ELFekr ElAQrabi, Cairo (in Arabic language)

24. W. Kakihana, S. Suzuki (2001): The EMG activity and mechanics of the running jump as a function of takeoff angle Journal of Electromyography and Kinesiology 11 (2001) 365-372

25. Walker.S, Peltonen.H, Avela.J, Häkkinen.K Kinetic (2011)and electromyography analysis of single repetition constant and variable resistance leg press actions .Journal of Electromyography and Kinesiology,Volume 21, Issue 2 , Pages 262-269, April 2011.

26. Wehbe Alwan Hassoun , Osama Ahmed Hussein (2009): Relationship of motor transport index with electrical average of Quadriceps femoris muscle rectus femoris and femoris biceps in hop and step with triple jump achievement, published research , Crete University. (in Arabic Language) 